\title{
Dominique G. Poitout and Henri Judet (Eds.): Mini-invasive surgery of the hip
}

\author{
Springer-Verlag Paris, Berlin, Heidelberg, New York, Hong Kong, Londres, Milan, \\ Tokyo, 2014, VIII, 170 p. 123 illus., 77 illus. in color, eBook : 51,16 €, Hardcover: \\ 63,25 €, ISBN 978-2-287-79930-3
}

\section{Pierre Kehr}

Received: 10 September 2014 / Accepted: 15 September 2014/Published online: 24 September 2014

(C) Springer-Verlag France 2014

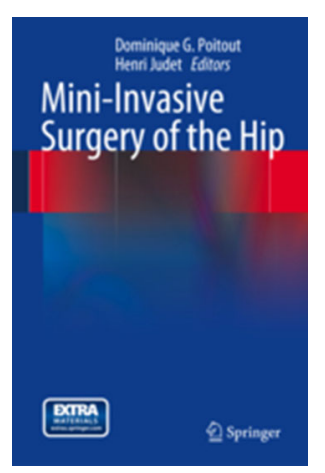

The mini-invasive surgery of the hip saw during last years its share in the surgery hip to progress it in a considerable way. This book Co-writing by eminent specialists studies this mini-invasive approach in the various anatomic accesses of the articulation. Most accesses are illustrated by diagrams, drawings in colors, photographs, and radiographies. One can regret the absence of unit of the operational drawings whose quality is variable, but which nevertheless keeps all a real didactic character.
The former mini-invasive approach for total prosthesis of hip begins the book and is based on the absence of any muscular or tendinous section, illustrated of splendid operational drawings.

The various accesses make him continuations, all with bibliographical good reference points and discussions.

This very didactic work takes point of the modern approaches for arthroplasty of the hip, it will consolidate each surgeon whom has already made his choice and will allow that which, curious, wants to initially change to be able to do it in all full knowledge of the facts.

Conflict of interest None.
P. Kehr $(\bowtie)$

Strasbourg, France

e-mail: kehrpier@aol.com 